\title{
Importing Western Childhoods into a Chinese State-Run Orphanage
}

\author{
Leslie Wang
}

Published online: 3 March 2010

(C) The Author(s) 2010. This article is published with open access at Springerlink.com

\begin{abstract}
Since the early 1990s the Chinese government has allowed foreign humanitarian non-governmental organizations to aid children residing in official state-run orphanages. As one aspect of a larger research project on child abandonment and forms of orphanage care in contemporary China, this article examines an innovative state-civil society partnership of a Western infant special care unit housed within a large official state-run institution. The "Tomorrow's Children" special care unit, funded and managed by middle-class Western volunteers, uses First World medical practices and universalistic ideologies of children and childhood to care for the institution's most severely ill and disabled children. This article utilizes ethnographic methods to discuss conflicts over children's best interests that arise between Western volunteer employers and the local working-class and poor Chinese caregivers who are expected to implement the imported practices. I contend that disagreements over appropriate childcare hinge on cultural and class-based understandings of childhood and differential access to social and financial resources. This research grounds discussions of globalization in a detailed case study by exposing the tensions and negotiations that occur at the local level in processes of transnational exchange.
\end{abstract}

Keywords China $\cdot$ Orphanage $\cdot$ Child welfare $\cdot$ Care work $\cdot$ Globalization

\section{Introduction}

Since beginning its rapid transition to a capitalist market economy in 1978, China has encouraged immense foreign investment that has led to the small-scale migration of whitecollar workers from industrialized countries into urban areas. The nation's new, though guarded, openness to foreign influences has also paved the way for Western religious nongovernmental organizations (NGOs) to become deeply involved in caring for abandoned children residing in state-run institutions.

\footnotetext{
L. Wang $(\bowtie)$

Department of Sociology, UC Berkeley, 410 Barrows Hall, Berkeley, CA 94720-1980, USA

e-mail: lkwang77@berkeley.edu
} 
Over the past two decades, a large number of foreign volunteers motivated by deep Christian religious conviction have ventured to China to work with marginalized youth. These individuals bring with them not only considerable financial and medical resources from abroad, but also individualistic Western ideologies about children and childcare that frequently conflict with the viewpoints and practices of their Chinese collaborators. While China, an officially atheistic state, does not allow missionaries to proselytize within the country, volunteers often state that their faith motivates them to do acts of good work that benefit the "bottom $1 \%$ " of the Chinese population. ${ }^{1}$

Collaborations between foreign philanthropic groups and local state-run orphanages (referred to in China as Children's Welfare Institutes, or CWI), while few in number, appear to be growing in acceptability as China continues to "open up" to international influences in its rapid process of modernization. In Beijing alone, there are roughly 10-15 different private foster homes run by Western expatriates that employ First World childcare practices to tend to sick and disabled children from various welfare institutes across the country, arranging for their medical care and post-operative treatment. While these children technically remain wards of the Chinese state, most of these homes operate facilities independent from welfare institutions, setting their own terms of employment with local staff and only sporadically interacting with state authorities.

As one aspect of a larger research project on child abandonment and forms of orphanage care in contemporary China, this article examines a unique and innovative state-civil society partnership of a Western-managed infant special care unit housed within a large official state-institution. The "Tomorrow's Children" facility ${ }^{2}$ - located in an agricultural, economically resource-poor and highly populated province of central China-uses Western medical knowledge and practices to care for the institution's most severely ill and disabled children. The unit assumes full responsibility for these children until they either die or become well enough to receive surgery or advanced medical treatment.

Funded and managed by white, educated evangelical Christian volunteers, many of whom have had limited experience in China, the unit cares for roughly 45 children at a time and employs more than 70 local working-class women as ayi (literally translated as "aunt" in Chinese, but also used more broadly to refer to "nanny" or "caregiver"). Tomorrow's Children is one of only a handful of foreign philanthropic groups to have gained full permission by state authorities to operate in a child welfare institute, remarkable at a time when the government has been limiting and even closing down the operations of a range of Western-run NGOs in China. ${ }^{3}$

This article draws upon a mixture of participant observation and interview data gathered in the Tomorrow's Children unit, where I worked as a full-time volunteer for a total of two and a half months between January and May 2007. I use ethnographic methods to

\footnotetext{
${ }^{1}$ Western Christian volunteers in China repeatedly used the term "bottom $1 \%$ " to refer to abandoned children. Many volunteers cited the following Bible quote as their inspiration for working with marginalized children: "Religion that God our Father accepts as pure and faultless is this: to look after orphans and widows in their distress and to keep oneself from being polluted by the world" (James 1:27).

${ }^{2}$ All proper names used in this article, including that of the Western special care unit, are pseudonyms.

${ }^{3}$ During the time of fieldwork (2006-2007) a range of foreign organizations and NGOs were shut down or had their activities severely limited by the Chinese government. Several Western foster homes in the Beijing area were required to return children to their original orphanages. Most notably, China Development Brief, an independent Western-run publication founded in 1996 that published articles on NGOs and the development of Chinese civil society, was forced to cease operation of its Chinese language website in July 2007; this effectively disabled the organization. Many speculated that these new stringent governmental limitations were directly related to the upcoming 2008 Beijing Olympics and official fears over intensified international scrutiny.
} 
investigate the unprecedented ways in which many children who reside in state-run institutions are being affected by imported ideologies of individualism and belief in children's unlimited potential. I analyze negotiations over the care of abandoned children in the Tomorrow's Children unit to demonstrate how the concept of childhood, though often viewed as a universal and ahistorical experience (Malkki and Martin 2003), is actually a socially constructed, contested and stratified domain firmly rooted in local political and cultural circumstances.

I also examine the conflicts that arise between Western volunteer employers and the lowpaid, local working-class and poor Chinese women who are expected to implement the foreign practices. While I found evidence that each side tends to view childcare disagreements through the lens of cultural differences between China and the West, I contend that cultural differences intersect with divergent class-based understandings of children's best interests that inform practices of care. As I will explore further, existing tensions are exacerbated by material inequalities within the unit, including the organization's seemingly limitless financial investment in marginalized children and socioeconomic disparities between Western volunteers and Chinese caregivers. ${ }^{4}$

I begin this paper with a brief review of the literature on orphaned and abandoned children in the context of changing meanings of childhood in China and shifting approaches to child welfare provision. I then discuss the methodological approach of this project and give a detailed description of the collaboration between Tomorrow's Children and the local Chinese government. Finally, I examine the different cultural and class-coded practices and perspectives of Western volunteers and local Chinese staff regarding children's best interests. These disparities bring complexity to their interactions with one of China's most marginalized populations.

\section{Changing meanings of childhood, child abandonment and child welfare in China}

The Tomorrow's Children Western special care unit is best understood within the context of changing meanings of childhood and the trend of child abandonment that has occurred in China since the period of "reform and opening" (gaige kaifang) began in 1978. In the transition from a socialist to a market economy, Chinese society has undergone enormous transformations and experienced an influx of commodities, ideologies and practices from abroad. The central state has increasingly retreated from the public sector, eliminating government jobs and social welfare benefits. Yet, since the late 1970s it has also exerted increasing influence over the private domain of families through the institution of wideranging birth control regulations (jihua shengyu), most notably the one-child policy of 1979. A major motivation behind these regulations has been the Chinese government's desire to "raise the quality" of the entire population (tigao renkou suzhi) in order to bring China into a position of global dominance (Kipnis 2006; Greenhalgh 2003, 2005; Anagnost 1995, 1997, 2004; Woronov 2003).

China's rapid marketization has increased parental anxiety about the future and led to an intensified emphasis on cultivating "high quality" offspring who are healthy, educated, cosmopolitan, creative and entrepreneurial (Bakken 2000). As Woronov (2003, p. 18)

\footnotetext{
${ }^{4}$ In utilizing terms such as "Western" and "Chinese," I concur with Hoffman and Zhao (2008), who argue that while there are dangers of creating "unwarranted generalization, leading to monolithic comparisons that erase internal differences," carefully qualified cultural categories can be "useful as heuristic devices to illustrate broad cultural contrasts" (p. 3).
} 
elaborates, "high quality subjects are those who will implement the new economy, bring China into its position of global respect, and fulfill its historical destiny." Children, as the next generation of Chinese citizens, are deeply implicated in this state-driven process of raising the nation's quality.

Structural transformations and restricted child-bearing now stratify youth according to their perceived future worth as productive laborers. As Anagnost (1997) has argued, economic privatization and increased parental anxiety has resulted in a deepening obsession with cultivating the mental and physical quality of offspring.

$[\mathrm{T}]$ he child becomes a repository of stored value against the uncertainties of rapid economic development. Even as China appears to be approaching its long-awaited "historical destiny" as a modern world power, it also brings great uncertainties about family security and political stability that become focused on the child. (p. 197)

Until recently, the limited scholarly literature on children in contemporary China has tended to focus on spoiled urban "little emperors" and "empresses" (xiao huangdi) who receive enormous state and parental investment (e.g. Fong 2002, 2004; Jing 2000). Attention is only beginning to be paid to China's orphaned and abandoned children due to the difficulty of gaining access to accurate statistics and state-run institutions. Research suggests, however, that over the past 30 years, stringent fertility restrictions, a cultural preference for sons and the decreasing social welfare safety net have produced an escalating abnormal sex ratio among infants (Wang 2009) and the abandonment of an unknown number of female and special needs children to state care (Shang and Cheng 2006; Shang et al. 2005b; Johnson et al. 1998).

Shang et al. (2005a) has estimated that there are roughly 50,000 children living in children's welfare institutes (CWI), at least $95 \%$ of whom have been abandoned. This figure is arguably quite low in comparison to China's enormous 1.3 billion person populace in part because it leaves out a large number of rural children who reside where official welfare institutes are scare, a complex topic that is beyond the scope of this paper.

In a separate study, Shang and Cheng (2006) tracked trends in orphanage populations, discovering that up to $80.5 \%$ of the children in CWI were abandoned because of disability and/or illness; this finding has led the authors to argue that the increasing lack of governmental social welfare provisions or help for families with disabled children in rural areas directly relates to their abandonment. This research is also important in helping to debunk the Western misperception that Chinese orphanages are overflowing with healthy baby girls. While girls are the second-most likely group to be abandoned to state care, they tend to be adopted either domestically or abroad as infants, ${ }^{5}$ leaving their disabled or ill counterparts behind (Dorow 2006; Johnson 2004). ${ }^{6}$

The trend of child abandonment is thus symbolic of the ways in which children's social value is increasingly measured according to market principles. It is also an unintended consequence of the Chinese government's shift to a less formal role as regulator of social support. While in the past the central government was fully responsible for caring for institutionalized children and disallowed welfare institutions from seeking other sources of financial support, since the mid-1990s several powerful Chinese state ministries began

\footnotetext{
${ }^{5}$ For further sociological discussion of issues related to American adoptions of Chinese daughters, see Traver (2007), Dorow (2006) and Johnson (2004).

${ }^{6}$ It is important to note that special needs children are also adopted transnationally, although not in the same numbers as healthy girls. See Dorow (2006) for a more detailed discussion of special needs children residing in Chinese welfare institutes.
} 
requiring local-level governments to take full responsibility for orphaned and abandoned children, which displaced nearly all fiscal liability onto localities (Shang 2001).

The decentralization of social services has thus forced local-level governments to "innovate" ways to take care of parentless children (Keyser 2006). Since 1993 the declining amount of central government support has been accompanied by official income-generating activities, leading cash-strapped local governments to turn to a "multi-pillar system" (Shang 2001) of profitable ventures such as transnational adoptions, donation solicitation and increasing involvement with foreign NGOs. The collaboration between the "Haifeng" CWI (a pseudonym) and the Tomorrow's Children Foundation is a result of this major transformation in the Chinese child welfare regime.

\section{Methodology}

This paper is based on ethnographic fieldwork conducted over three separate research trips taken between January and May 2007 to the Tomorrow's Children special care unit. In total I carried out two and a half months of participant observation and informal interviews. ${ }^{7}$ During my time there I worked as a full-time volunteer, living in the unit and doing a variety of tasks. As I was the only volunteer fluent in both English and Mandarin, my responsibilities included translating documents, oral translation between Western and Chinese staff, helping ayi with childcare, dispensing medication, taking children to the hospital, dealing with Chinese medical practitioners, orienting new volunteers to the area, as well as simple office administration. The Western management and Chinese staff were all aware of my researcher status.

Due to the political sensitivity of dealing with illegally abandoned children, it was extremely difficult to conduct formal interviews with either Westerners or Chinese workers. Rather, I conducted multiple informal interviews with all eight of the Western volunteers (who were American, British and Canadian) present during those periods. These conversations usually took place during breaks or meal times, lasting an average of 30 minutes to 1 hour. I specifically asked them about their motivations for coming to China, their analysis of struggles for authority between the special care unit and the welfare institute, and their views of Western versus Chinese caretaking practices.

Each day I also spent time in each of the five children's rooms, where I informally interviewed a total of twenty ayi in Mandarin in conversations lasting from 10 minutes to 1 hour. I inquired about their personal lives, experiences caring for sick and disabled children, opinions (and sometimes confusion) regarding Western childcare practices and their views of general working conditions. I also spent many hours in conversation with the Chinese work schedule coordinator and the constantly rotating staff of cooks and housekeepers. Because of the political sensitivity of issues, I did not tape-record any interviews, but instead transcribed them from memory directly afterward. Later I transcribed and coded all of my written materials, including interviews, observational data and general field notes.

\section{Stratified childhoods within state-run facilities}

The Tomorrow's Children (TC) facility occupies one entire floor of a large six-floor children's welfare institute located in the center of a mid-size industrializing city in a highly

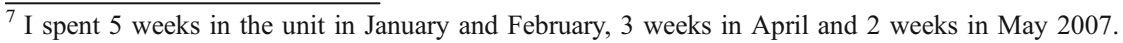


populated, primarily agricultural central Chinese province. The special care unit opened in September 2006 as a branch of a more sizeable Western-run foster home situated on the outskirts of Beijing, founded by an Australian evangelical Christian doctor in 2000. The mission of the Beijing home is to take in abandoned children with operable illnesses and treatable diseases who would have only perhaps a $2 \%$ chance of survival had they stayed in an institution.

The group uses its global contacts to obtain surgeries for children in places with more advanced medical technology such as the US, Singapore and Hong Kong, and helps to facilitate their adoptions by mostly white American Christian families. It is important to note that while Tomorrow's Children is an openly religious organization, it has an official policy of not engaging in efforts to convert locals or raising children in the Christian faith. Instead, volunteers tend to engage in what Bornstein (2002) has termed "lifestyle evangelism," which involves "the process of living a life in the manner of Christ, providing an example, and showing non-believers Christianity through the life that was led" (p. 11). Through leading by example while not engaging in direct proselytization, the organization is able to continue its close working relationship with the Chinese government.

Impressed by this operation, in 2005 the Chinese Ministry of Civil Affairs - the branch of government responsible for orphans, the disabled and the elderly-approached the organization to build a similar Western-style facility within the confines of the Haifeng CWI to care for infants with little to no likelihood of survival or future adoption. After reaching an agreement that the group would use its own funds to build and maintain the special care unit, but not pay the welfare institute to operate there (as is often expected of foreign NGOs), the organization built an exact, smaller-scale replica of its Beijing home inside the Haifeng institution.

This particular state-run facility is responsible for nearly 600 children, at least half of whom reside in local foster homes or boarding schools. Of the children living on-site, $90 \%$ suffer from some kind of illness or long-term special need. ${ }^{8}$ Children tend to be housed according to disability and severity of prognosis, so that children with cerebral palsy (of which there were at least 100 living in the institution) are kept together while developmentally "normal" children live in more dorm-like settings and leave the grounds on a daily basis to attend local schools.

Located in a major metropolitan center, this CWI receives at least one or two extremely ill or developmentally disabled infants each day who have been abandoned at local hospitals or in the surrounding area. The sickest infants (of whom there are about 15-20 at any one time) are housed two to a bed in a cramped, grimy and depressing room at the end of one hallway on the second floor, in what volunteers refer to as the "dying room." The agreement between the facility and Tomorrow's Children stipulates that the orphanage doctor will bring the children with the lowest chance of survival up to the special care unit three floors above. The unit then cares for these children until they either pass away or recuperate well enough to return to the facility below or be released to local foster care.

Like several other state-run institutions I visited during my research, foreign investment has paved the way for the involvement of a number of Western philanthropic groups to donate resources, equipment and personnel. In addition to the help of Tomorrow's Children, a Western hospital for the foreign expatriate community in Beijing provides free formula for

\footnotetext{
${ }^{8}$ Stated in a publication of the Haifeng CWI.

${ }^{9}$ This is in direct reference to the 1995 British documentary "The Dying Rooms: China's Deepest Secret," a controversial secret expose of institutional neglect, mistreatment and incredibly high death rates of orphans and abandoned children in Chinese welfare institutes.
} 
all babies on a monthly basis, the Gates Foundation sponsors a physical therapy unit for cerebral palsy-afflicted children and provides a large van for their use, a Hong Kong-based group operates a recreation center on the ground floor and helps to place healthy babies in local foster homes, and an American teacher is brought in on a daily basis to teach English to the older children.

The CWI has won myriad public accolades for its work on behalf of children, including being designated a "First Level Welfare Institute" (yiji fuliyuan) of the province in 1999 and a "National Progressive Organization" (xianjin tuanti) in 2004. The institute's director has stated that his goal is for all capable children in the institution to become successful by providing them with excellent educational opportunities. Children are also required to take part in frequent community performances staged in front of the building on all major holidays, which include various kinds of Chinese and Western dances (most notably a highenergy solo performed by a silver-clad young man with one leg), a brass band ensemble, individual and group singing and a physical therapy demonstration by a group of children with cerebral palsy and their nurses. The older, able-bodied children appear to be in good health; they are instructed to call out "hello" and "goodbye" in English to Western visitors as they zoom down the staircase. Older children with cerebral palsy also have their own specialized regimen where they are able to take part in daily physical therapy in the adjoining building.

However, the facilities for infants that exist separately from the Tomorrow's Children unit are sorely inadequate and understaffed. Each ayi in the welfare institute cares for six to ten children - many of whom are disabled or have serious illnesses - in 12-hour shifts, 7 days a week. Despite its substantial foreign aid, the institution puts most of its funds towards the able-bodied and rehabilitable while little is invested in the smallest and sickest youth. The grim, overcrowded "dying room" lacks what Western volunteers consider to be basic resources such as soap, toothpaste and disposable diapers, let alone a single toy, medication or any kind of medical equipment. One British volunteer described this paradox, "This orphanage is a fantastic place to be if you survive to the age of four. But up until that point, it's definitely survival of the fittest."

\title{
Giving children a childhood: Global ideologies in a Chinese context
}

\begin{abstract}
Most of the babies whom we have with us have been rejected and would have had difficult and painful experiences. They are helpless and are totally dependent on us to love them and protect them from harm. At ALL times, be gentle with them and treat them as precious creations of God and let them know that they are loved.
\end{abstract}

$$
\text { -excerpt from Tomorrow’s Children "Baby Care Policy for Nannies" } 10
$$

Within the confines of the Haifeng CWI, a variety of childhoods simultaneously coexist. This stratification of children's life opportunities problematizes the concept of "childhood" as a singular, universal and ahistorical experience. Scholars contend that globally hegemonic images of white, Western middle-class children influence our understandings of contemporary childhood as a separate, vulnerable and sentimentalized period; in the process, the oftentimes harsh and diverse realities of life faced by many of the

${ }^{10}$ The baby care policy for nannies is a document available in both Chinese and English on the Tomorrow's Children website. 
world's children are rendered invisible. In fact, children who grow up in non-nurtured, unprotected spaces are often considered to be completely without childhood (Thorne 2009; Stephens 1995). Burman (1994) writes about the concept of childhood as a social construction:

Within northern industrialized societies, childhood is regarded as a period of dependency: lacking maturity, children are seen as in need of nurturance and protection, in need of supportive family relationships and (especially when those are considered inadequate) caring institutions. Uncontroversial as this appears, its historical construction and novelty is sometimes forgotten in the ostensible universality of its appeal. The romantic model of the child is a profoundly modern and western construction. (p. 239)

It bears reminding, however, that childhood in the west has itself undergone fundamental transformations just over the past century and a half. Zelizer (1985) has famously elaborated on the changing social value of American children from "economically useful to emotionally priceless" that accompanied the move to outlaw child labor and introduce compulsory schooling. Likewise, parenting advice in the US also shifted significantly after 1930 as medical and technological advances eased earlier concerns over high rates of infant mortality. Expert opinion on childcare changed from a preoccupation with infant health, hygiene and the need for babies to maintain strict and routinized schedules to the need to pay attention to children's intellectual development and individualized emotional needs (Hardyment 2007; Wrigley 1989). Thus, ideologies of modern, Western childhood and notions of children's "best interests" which now predominate across the globe (Howell 2006) have themselves emerged quite recently in response to broader patterns of social change.

The Tomorrow's Children organization imports dominant First World ideologies of childhood into its work with marginalized Chinese children. In the Haifeng children's welfare institute, a stratification of life opportunities for children reflects conscious decisions adults have made as to who is more deserving of limited governmental resources. But as a separate, well-funded foreign organization, TC sidesteps these negotiations altogether and alleviates immense financial burden from the welfare institute by caring for the youth at the very bottom of the social (and orphanage) hierarchy. In fact, once children arrive in the unit from the "dying room," the economic and emotional investment in their well-being far surpasses what is provided to their peers residing on the floors below.

That the unit only administers to children who have some form of physical or mental disability is also highly significant. In her study of American adoptions of Chinese children, Dorow (2006) suggests that special needs children in state institutions "occupy a telling ideological space somewhere between the universal valuing of children and the particularizing value of adoption" (p. 99). International organizations go out of their way to aid special needs children, although (or perhaps because) their disabilities cause them to be less valued as objects of adoption. Such children, Dorow argues, bear symbolic importance as "placeholders of true care - a site for modeling the value of all children equally" (p. 100). Through its mission of aiding only the most devalued children, TC intersects with larger transnational projects that seek to inspire Chinese people to care more about the welfare of all of its citizens.

After describing the children, staff and set-up of the unit I will explore further how childcentered caring practices in the Tomorrow's Children unit inculcate lifestyles that rival those experienced in middle-class contexts into devalued special needs youth. 
The children and set-up of the unit

The unit cares for roughly 45 children at a time who remain under the legal jurisdiction of the CWI and can (theoretically at least, though rarely in practice) be called back to the facility below at any time. The majority of children, roughly $75 \%$, suffer from mild to major cerebral palsy that is often combined with other health issues. Aside from cerebral palsy, children in the unit suffer from a wide range of illnesses and disabilities. These include (but are not limited to) spina bifida, congenital heart disease, imperforate anus, hydrocephalus, liver failure, cleft lips/palates, autism, Down Syndrome, skull malformation, skin disorders, severe prematurity and a variety of undiagnosable terminal illnesses.

The facility is primarily set up to care for infants and toddlers, although actual ages range from 0 to $14 .^{11}$ Children are separated into five spacious, cheerful color-themed rooms according to age, size and illness or medical condition. Two smaller rooms primarily house toddlers with minor to severe cerebral palsy, while an adjoining room houses 12 infants - many of them able-bodied and in need of only minor corrective surgeries. Such children, once fully recuperated, will be returned to the welfare institute below or sent out to local foster care. The largest room houses 12 older children ages five and up who have cerebral palsy. Lastly, babies suffering from terminal illnesses who clearly do not have long to live or preemies in need of intensive care are housed together in a special intensive care room. This room has an adjoined sterile nursery that contains an incubator, an extra crib and oxygen canisters. It can be closed off if a child ever needs to be isolated for reasons due to infection.

The unit also includes a large kitchen and a full-time cook who prepares fresh food for the older children on a daily basis. There is also a separate children's play room, two large changing and wash rooms, a locked storage room, a laundry room with several new washers and dryers, and a one-bedroom private volunteer apartment that can house up to three or four people. Each room, including bathrooms, is maintained by way of financial sponsorships from individual donors, church groups and even UPS (United Parcel Service).

Western volunteers and Chinese staff

At the time of fieldwork, the unit was run primarily by Cathy, a devoutly Christian white British nurse practitioner, and her husband Brian, who retired in their mid-50s to devote their lives to working with orphaned and abandoned Chinese children. Cathy manages all of the medical care and treatment for each child in the unit, though major decisions regarding surgeries and palliative care are ultimately made by the Australian doctor in charge of the Beijing foster home. All other Westerners in the facility serve on a volunteer basis for anywhere between 2 weeks to a year. A typical stay is around 1 month in length.

The unit receives an average of three or four mostly evangelical Christian volunteers per month from countries such as the US, the United Kingdom, Australia, Canada, Singapore and Hong Kong. Nearly all volunteers are trained in a specialized skill, including nursing/ medicine, physical and occupational therapy, speech pathology and teaching. For the

\footnotetext{
${ }^{11}$ Because children are abandoned and their true birthdates are unknown, welfare institute doctors guess their age based on physical size. Those suffering from cerebral palsy are usually incredibly malnourished and emaciated, and thus their ages are often given as less than 6 years. Within a few weeks in the unit, however, they often double their weight and it becomes apparent that they are several years over their originally estimated age.
} 
majority of volunteers, this constitutes their first visit to China; thus, most lack any kind of Mandarin language skills or in-depth knowledge of Chinese culture.

The unit also employs roughly 75 local Chinese people. Because they are privately hired, trained and compensated by Tomorrow's Children, they are considered to be separate from the regular CWI staff (who are civil servants managed by the Chinese state). The vast majority work as ayi, but there are also housekeepers, cooks, a full-time ayi supervisor and a driver/maintenance man (the only Chinese adult male in the unit). ${ }^{12}$ As TC's founder informed me, in order to enforce uniformity, all Chinese workers except the ayi supervisor and driver are required to wear identical uniforms of red flowered shirts, red sweaters, black pants and black slippers. All of these women are mothers of one or two children in gradeschool; they mostly reside in the city's rural suburbs and commute in for work. Their overall level of attained education is quite low, ranging from junior high school to high school. Additionally, though very few speak even the simplest of English phrases, the Western staff assigns each of them an English name such as "Courtney," "Alice" and even "Cherry" to facilitate easy memorization by volunteers. However, these names are used primarily only in conversations between Westerners, as ayi are often unaware of their own English-language names.

The TC employee contract, which must be approved by the CWI director, stipulates that each ayi care for the same three children every shift, except under special circumstances. Most ayi work day shifts from 7 am to $7 \mathrm{pm}$, at which time they are relieved by night time caregivers who work from $7 \mathrm{pm}$ to $7 \mathrm{am}$. Because the founders of Tomorrow's Children prioritize bonding, attachment and consistency of care for the children, it is impossible to switch from daytime to evening shifts or vice-versa, a stringent rule that provokes constant grumbling among the staff. For their labor they are paid extremely low wages of $450 \mathrm{kuai}$ (at the time just over \$60 US) per month, with a 100 kuai cash bonus given at Chinese New Year plus 100 kuai worth of items such as apples, fish, cooking oil and rice. This type of work is significantly underpaid; in comparison, the average per capita income in the local area was nearly double the ayi wage, totaling 998.5 kuai per month in 2006 ("H" Statistical Yearbook 2007).

\section{Individualizing practices of care}

All babies are individuals and although we try to fit them into our routine to make our work easier, please allow for their individual personalities so that they will grow as normal children in a loving home environment and not as "institutionalized" children...Get to know your babies well and give them the care that they need.

\section{-excerpt from Tomorrow's Children "Baby Care Policy for Nannies"}

Though volunteers are outnumbered nearly 10 to 1 by Chinese workers in the unit, the guiding philosophy and practices of care are imported directly from abroad. As the Australian founder of Tomorrow's Children told me when I interviewed her in Beijing, "There are many different ways to do things. My way might not necessarily be the best, but here it is the ONLY way. Otherwise you don't have to work here!" As they undergo visible

${ }^{12}$ It is important to note that while this paper does not deal explicitly with gender, childcare and conceptions of childhood are gendered in nature. 
physical, cognitive and emotional transformations, marginalized children are "revalued" as objects of sentimental love and affection.

These caring practices, detailed below, include naming, changing appearance, individual ownership and the intensive tracking of children's bodies.

Naming

When a child arrives from the CWI, volunteers give him ${ }^{13}$ an English-language name that mirrors the sound of the Chinese name already given by the welfare institute. ${ }^{14}$ Most volunteers do not speak Chinese and thus tend to only memorize children's English names (though ayi continue to refer to them by their Chinese names). In this way the practice of naming instantly gives the child a new kind of identity that is not truly Western but also not fully Chinese.

\section{Changing appearance}

Through the mere changing of clothes and a bath, a major physical transformation occurs within just the first few minutes of a child's entrance to the unit. Children arrive from the orphanage below swaddled in thick, faded, one-size-fits-all Chinese quilted outfits. Due to lack of bathing, they are usually incredibly dirty and often covered in skin diseases. Once in the unit, they are gently bathed, shampooed, lotioned and powdered in a plethora of Johnson's and Johnson's baby products that cost two or three times more than local Chinese products. After Q-tips are used to clean out weeks of grime from their ears, they are clothed in expensive Huggies diapers and thin, bright, imported cotton onesies. In an immediate fashion, myriad resources are mobilized to begin caring for the child in a middle-class, Western way.

Individual ownership and possession

The third aspect of this process of revaluing marginalized children as individuals occurs through giving them ownership and possession over various items. Unlike the "dying room," where a group of children is often fed with the same bottle or spoon, in the TC unit everything is individually labeled to be used by only one child. Towels, washcloths and clothing are personalized by stitching the child's initials into them with thread matching the color of their assigned room. Each child has a separate labeled box for medication, their own pacifier, spoon, bowl, bottle, toothbrush and cup. Their names are taped onto their own baby walkers and specialized, imported feeding chairs. Moreover, on birthdays and the changing of seasons, children are given a new set of clothing while on Christmas they each receive a large, battery-operated toy.

\footnotetext{
${ }^{13}$ I am intentionally using the pronoun "him" to refer to children in the unit as the vast majority were male. At the time I was there, there were only 15 girls out of a total of 45 children residing in the unit.

${ }^{14}$ This CWI names children according to the year that they enter the facility. As is the case in many welfare institutes, all children are given the last name "Dang," which stands for "gongchandang" (Chinese Communist Party) (see The Economist, March 24, 2007). Due to issues of organization, all children who enter the institution during a particular year share the same first character of their two character given name; there is one character chosen for boys and a separate character for girls. The last character in each child's name is given by CWI staff. Only in one case did I meet a child who kept the name given by her parentsthis is because she was abandoned to the institution at the older age of 7 or 8 .
} 
Tracking children's bodies

The last major set of Western individualizing practices employed in the unit involves a high level of surveillance and measurement (Foucault 1978) as children's bodies and overall well-being are intensively tracked and monitored. Since children have been abandoned, tend to very little is known about their personal backgrounds or medical histories. They usually arrive only with a brief form listing their Chinese name (given by the CWI) and general medical symptoms. Once transferred to the special care unit, each child is given an intensive medical examination to diagnose illness and plan out a specialized care regimen. The nurse begins a file that includes the child's name, photo upon arrival, date of birth, description of illness and suggestions for treatment. Each day the nurse goes through the unit and checks on each individual's condition, recording notes in the file. Babies' weights are taken once a week, while older youths are weighed on a monthly basis, all of which is recorded in their folder.

Additionally, Chinese caregivers are required to use a separate clipboard that contains a series of forms that track each youth's physical progress during each work shift. An "input/ output" sheet monitors the frequency and time of urination and bowel movements (often including details regarding color, amount and consistency), as well as the intake and timing of formula or solid food. The second sheet tracks body temperature, taken by the ayi every 4 hours or more depending on the child's condition. The third sheet lists the medications the child should receive, with the dosage times written above boxes that the ayi check off throughout their shift. The final sheet is used to pass messages between daytime and evening ayi to keep one another informed of changes in a child's medication or general condition.

This process is analogous to what Nieuwenhuys (2003) observed in her study of foreign NGOs that administer to street children in Addis Ababa, Ethiopia. She argues that the constant surveillance and regulation of children's schedules is a primary component of aid work that plays a fundamental role in transforming stigmatized, disparaged youths into "normal" (i.e. First-World) children. She writes, "Submitting to the schedules purifies a child from the filth and vice that breeds unchecked in the disorderly [outside] world... turning the child in time into a new person" (p. 110).

Though the ultimate objective of this detailed and precise system of tracking is to improve children's health (or at least to make them as comfortable as possible), the implementation of this system faces constant glitches that lead to untold frustration. Many times after a child had fallen ill or major modifications were made to his medication, I checked the charts and saw that the ayi on shift had listed the child's condition as zhengchang ("normal"). When asked why they wrote this, many ayi answered that they were pressed for time at the end of the day bathing and feeding children before the end of their shift, and felt it was better if they relayed the situation orally to the next caretaker rather than summarize it on paper. Over time I came to realize that resistance to recording notes about the children may have been related to a sense of having inadequate education and writing skills; they likely also did not want to be held responsible if they wrote complicated medical conditions incorrectly.

Nonetheless Cathy, the British nurse, began asking volunteers to "stand watch" over ayi on days when the children under their care fell ill, and to physically take the form to them and point at it to make sure they filled it out in a more detailed fashion (this, however, was purely a symbolic demonstration of authority, as I was the only volunteer who could actually read Chinese). This situation highlights the complicated dynamics that arise in transnational sites of care, as foreigners attempt to import a First World vision of 
appropriate behavior that is conditional on access to education, training and resources unobtainable by the local workers.

\section{Instilling global values through childcare practices}

Article 3(1) of the UN Convention on the Rights of the Child (UNCRC), adopted in 1989 and ratified by China in 1992, states that:

In all actions concerning children, whether undertaken by public or private social welfare institutions, courts of law, administrative authorities or legislative bodies, the best interests of the child shall be a primary consideration.

The special moral status granted to children in this document, which has been signed by every nation in the world except the United States and Somalia, is infused with ideologies of inalienable individual rights. Children are represented as competent and responsible social actors "with viewpoints and specific interests that should be taken into account" (Gullov 2003, p. 33). As Thorne (2009) explains,

The 54 articles of the UNCRC specify rights related to protection from physical, sexual, and psychological exploitation; from the effects of war; and from exploitative work; provision, e.g. the right to food, clean water, health care, and education; and participation, based on an understanding of the child as an active and contributing participant in society. (pp. 14-15)

The convention has been criticized for embedding individualist values that are not fully applicable to collectivistic societies (Alston 1994). China provides a relevant case in point, because although it ratified the UNCRC without issue, research that has been conducted in Chinese welfare institutes has demonstrated a disjuncture between the individualist values embedded in the document and actual implementation at a local level. This suggests the difficulty of imposing universal standards of childhood across all national contexts and the ongoing salience of cultural differences and material limitations, even when parties agree on guidelines.

Howell (2006) summarizes a 2001 Norwegian study of on-the-ground implementation of the UNCRC in three Chinese children's welfare institutes. The Norwegian research team found that while Chinese personnel tended to be superficially aware of the UNCRC, there was minimal discussion of children's best interests. Akin to the Haifeng CWI, in all three settings children were dealt with in a highly regimented manner. Additionally, their physical health, education and possibilities for future training were heavily prioritized while emotional needs (as understood in the West) were completely neglected. This caused researchers to conclude that within state-managed institutions "the focus on individuality and individual needs and rights so strongly apparent in the UNCRC, carries little meaning in the Chinese context" (p. 214).

In the Tomorrow's Children unit, the ideology of individual rights, autonomy and personal choice that underlie the UNCRC also motivate the work that volunteers perform. The child-centered approach of the unit not only attends to children's physical well-being, but also seeks to encourage their emotional development. This approach reflects specifically middle-class understandings of appropriate care. Thus, volunteers go to great lengths to encourage special needs children to live up to their fullest potential-regardless of whether that potential might be severely limited. If and when their physical health has been stabilized, volunteers expose children to a wide range of play and educational 
activities to discover their innate talents and interests that are then supported and developed over time.

For example, a group of European volunteers brought a huge variety of foreign toys to China, which they used to discern the likes and predispositions of each mentally competent child. The volunteers drew up a list of activities - painting, drawing, playing with balloons, toy cars, puzzles, balls and water play — on a chart labeled with each child's name and level of engagement with each category. At the end of the assessment, the chart became a guide for future volunteers to organize individualized children's play and activities.

This rigorous effort to find and encourage each child's individual interests reflects the global dominance of child-rearing practices that are contingent on access to social and financial resources and forms of expert knowledge. Hays (1996) has argued that in the US, appropriate child-rearing is considered to be "child-centered, expert-guided, emotionally absorbing, labor-intensive, and financially expensive" (p. 8). Likewise, Lareau (2003) uses the concept of "concerted cultivation" to describe the child-rearing practices of US parents with relatively more social and cultural capital who enroll their offspring in a range of activities to develop skills that will ultimately allow them to become more economically viable in the future; this exposure to new experiences, she suggests, guides middle-class children onto a trajectory that will reproduce their own class status in the future. Kusserow (2004) also discusses class-based childrearing, differentiating between what she terms the "hard individualism" of the American working class and the "soft individualism" of the middle class, which includes a "more psychologized conception of self, emphasiz[ing]...the extreme care, resources, wide canvas, and gentle touch needed to help the unique self of the child flower and open up into her full potential" (p. v).

Today in China's affluent urban areas, millions of well-educated parents are being influenced by the market as well as encouraged by the state to take this sort of individualized approach to raising their only child. State officials believe that the nation's economic progress depends on cultivating a skilled class of globally competitive workers. Children in the special care unit were abandoned primarily because of physical and mental impairments that will keep the vast majority from ever being able to live independently, let alone achieve gainful employment. However, as Dorow (2006) has noted, the presence of foreign charitable aid to orphanages can lead socially liminal children to be raised in ways that parallel their fortunate "little emperor" counterparts. She writes, "Ironically, pockets of abandoned, marginalized children [residing in state institutions] are the objects of some of the same kind of Western child development expertise now being marketed to middle- and upper-class urban Chinese one-child families" (p. 103).

This irony was not lost on the children's ayi, who watched with blatant puzzlement and curiosity as volunteers bounced children up and down on physical therapy balls, blew bubbles in their faces or serenaded them with plastic musical instruments. The volunteers' committed search to discover children's innate capabilities and the unwavering belief that each individual can "improve" was often a source of confusion for working-class caregivers.

To further illustrate this point, on my first day in the unit, the Western nurse assigned me to play with Jenny, a 4-year-old girl with severe cerebral palsy. She was concerned that this child was getting overlooked by volunteers and ayi alike, even though she "really had a lot of potential for improvement." I grabbed a bag of toys designed to stimulate infants and sat down on the floor pillows where Jenny-unable to sit up on her own, grasp objects or be potty trained-was lying prone, completely quiet and still. The two ayi in Jenny's room immediately sat down next to me and grabbed baby rattlers, shaking them loudly in front of her blank, unblinking eyes. All the while they kept repeating, "She's not aware of anything, she just doesn't know anything." ("Ta shenme dou bu zhidao"). I mentioned that the nurse thought the girl could make some progress. Jenny's ayi shook her head with some disbelief 
and said, "Yes, but progress to what level? What kind of progress can she really make?" ("Jinbu dao shenme chengdu?")

Sarah, a white 38-year-old volunteer nurse practitioner from the UK, offered an opinion about kids like Jenny:

With a lot of these children you may not see much of what we would normally think of as improvement. But we need to be okay with the fact that we might work with a cerebral palsy child intensively their whole lives, and the only noticeable difference is that they can make eye contact. All of these children have their own personalities; with some you just have to look a little harder.

\section{Cultural and class-based struggles over children's best interests}

In the unit, volunteers and ayi engage in a constant tug-of-war as each side holds a distinctive view of children's best interests. They are aware of having different perspectives, which each side assumes is the result of static cultural differences between China and the West. However, I found that sometimes dissimilar cultural ideologies regarding children tended to be amplified by class-based differences, socioeconomic disparities and the limitations of institutional caregiving.

\section{Children's changing needs in globalizing China}

Within the special care unit, defining children's best interests is a negotiated and highly conflict-ridden process. At issue are different conceptions of what children need (such as protection, emotional well-being, etc.), which many understand to be universal and scientifically-based. Woodhead (1997), however, argues that the very concept of "need" should be viewed as a cultural construction that derives from the heavily value-laden context of Western developmental psychology. In his view, unquestioned, normative notions of children's best interests conceal "a complex of latent assumptions and judgments about children. Once revealed, these tell us as much about the cultural location and personal values of the user as about the nature of childhood" (p. 63).

As previously described, the unit's middle-class Western volunteers greatly prioritize childdirected practices and active engagement with individual children, expectations that they impose onto the Chinese staff. Throughout the course of each day, volunteers can be heard complaining that the ayi are too restrictive, too passive or appear uninterested in promoting children's emotional growth and independence. They point out the large chests full of new toys in each room that are hardly ever taken out and lament that infants' gross motor and cognitive skills are being delayed from lack of stimulation. Newcomers to the unit invariably express shock at what they consider to be the harsh, rough way that many caregivers treat the children. When I asked the Australian founder of TC to name the biggest cultural challenges she has faced in running her facility, she stated, "Mostly it's been difficult in terms of training the nannies to raise children in a Western way. Chinese people are often very hard on their kids, very strict."

For their part, in private informal conversations many ayi state that their primary consideration is to keep the sick and disabled children under their care fed, clean and warm. They complain that in having to bathe, feed, administer multiple medications and change three children's diapers up to six times a day during 12-hour shifts, to add "playing" to their list of responsibilities is asking too much. Therefore, they believe that if volunteers want children to be entertained, they should do it themselves. While observing a volunteer help a 
child learn how to draw, one caregiver shook her head in a bemused fashion and said, "Westerners always do what the child wants to do. It's really different from Chinese people. In China, children do what the parents say."

More importantly, however, several ayi explained to me that they thought extensive proactive involvement with children encourages demanding and less compliant behavior that can negatively affect the other caregivers and children who must share the same limited space. Their comments draw attention to the limitations of caregiving within an institutional setting. A recent in-depth case study of a small, privately-run native Chinese Christian orphanage provides a relevant comparison to the TC unit. Niemetz (2007) observed that time-pressed ayi responsible for caring for large groups of children are often only capable of prioritizing their basic needs, such as making sure that they are fed. Akin to TC's ayi, the caregivers in Niemetz' study did not consider it to be their responsibility to facilitate play amongst children, instead leaving them to organize their own activities without adult interference.

In recent decades, varied researchers have investigated the extent to which Chinese parenting styles are changing along with larger structural transformations. Although the care given to children in Chinese institutions does not necessarily mirror parental care, these studies are nonetheless useful in exploring the relationship between different cultural and class-based values in childrearing. Many scholars have argued that in this time of social flux and rapid modernization, conservative traditions of child education and rearing have actually reemerged in the current period. Wu (1996) contends that the basic tenets of "ancient Confucian thought" are still quite apparent in contemporary Chinese parenting practices-which include expectations that children obey elders, exhibit impulse control and accept social obligations, while little emphasis is placed on independence, assertiveness and creativity (p. 148).

In a study comparing Chinese and white American mothers, Chao (1994) also finds support for the lasting influence of Confucianism on Chinese childcare practices, especially the importance of familial harmony through obedience to hierarchical relationships and set roles. She contends that while Westerners tend to describe the Chinese parenting style pejoratively as authoritarian, controlling or restrictive, Chinese mothers associate stricter control and governance of their children with parental care, concern and involvement (p. 1113). In comparison, the child psychology and development framework prevalent in Western industrialized nations emphasizes child-centeredness, individuality, independence, freedom, individual choice and self-expression that encourage children to discover their unique "self."

In a study of behavioral inhibition in Canadian and Chinese toddlers, Chen et al. (1998) argue that,

In Western individualistic cultures, children are encouraged to be assertive and independent in challenging social situations. Acquiring self-reliance, autonomy, and assertive social skills are important socialization goals... [while in comparison,] achieving and maintaining social order and interpersonal harmony are the primary concerns in both traditional and contemporary collectivistic Chinese societies. Individuals are encouraged to restrain personal desires for the benefits and interests of the collective.... The expression of individuals' needs or striving for autonomous behaviors is considered selfish and socially unacceptable. (p. 678)

However, a number of researchers such as Lau and Yeung (1996) are wary of using Confucianism as a unitary explanation for Chinese child development; they are concerned about overgeneralizing or promoting misconceptions about Chinese youth. Lau and Yeung suggest, instead, that researchers take a more holistic and complex view of Chinese society that accounts for both the lasting impact of cultural traditions and the rapid social transformations affecting individuals in the present day (p. 33). 
In addition to cultural factors, in China there are diverse and competing notions of good child-rearing that are contingent on social class, educational attainment and economic development. Recent research on younger, more educated middle-class Chinese parents who reside in cosmopolitan urban areas finds that they tend to value more autonomy in their children while older, less well-educated working-class parents are more likely to emphasize conformity in their child-rearing practices (Xiao 2000). This resembles the change that occurred in the 20th century US, whereby an increasingly industrialized and competitive economy caused parents to shift from valuing obedience in their children to emphasizing independence and autonomy (Alwin 1988).

\section{Children living at the intersection of difference}

The case of Henry, an adolescent boy with cerebral palsy, illustrates the kinds of complex negotiations and misunderstandings that I repeatedly observed in the unit over standards of appropriate childcare. Henry arrived in late January completely emaciated, ghostly pale, nearly catatonic and weighing only 7 kilos; the welfare institute's doctor estimated that he was roughly 6 years old. Yet within only 2 weeks of receiving a specialized care plan of nutritional feedings and medication, the boy had doubled his weight and grown so much in height that everyone believed he was actually a teenager. While Henry's physical health continued to rapidly improve, his ayi used physical therapy techniques taught to her by a volunteer to stretch his taut limbs and teach him to grasp objects. The Western staff was amazed by his progress as well as proud of his caregiver's supportive, hands-on care.

When I returned to the unit in April, however, I saw that the situation had dramatically changed. Henry's weight and physical condition had stabilized and he had become a highly intelligent and perceptive adolescent. Nursed back to health and hungry for mental stimulation, he began showing deep frustration with the toys and activities offered to him that were designed for use by small children. His ayi believed he had begun to misbehave and demand too much of her time, taking her away from the other two children under her care. She ceased giving him physical therapy and began to sit him for hours on end in front of the television with his back facing the rest of the room. Volunteers, on the other hand, couldn't understand the shift in her practices.

Over time Henry had come to equate volunteers with freedom, autonomy, play and personalized attention. When a volunteer entered the room, he would begin to howl, craning his head to make pleading eye contact. If lying on floor mats, he would roll himself across the room and grab one's ankles, begging for attention. Upon asking whether anything could be done to assuage him, the ayi in the room replied, "He's fine, just ignore him!" And, with more than 40 children to tend to and only several volunteers spread among them, it was impossible to give Henry the kind of individual attention he had come to crave. The whole staff became highly distraught when the boy began to bite his own hands in frustration, more than once drawing blood. Volunteers attempted to devote more one-onone time to him, but this would only temporarily placate his mood and need for stimulation.

The Westerners understood this situation to be the result of insurmountable cultural differences between themselves and ayi. One volunteer even expressed doubts about the feasibility of the entire special care unit:

I know that we're doing good by doing this, but there are such huge cultural differences, how much can you do just by helping this little group?...I'm not putting down Tomorrow's Children, but now that I've seen so much more of the cultural 
differences, I wonder if it can really work. A Western-led voluntary organization in

China - can it really work?

While cultural factors and the emphasis on group membership and harmony likely played a role in Henry's predicament - causing his behavior to be viewed as selfish and disrespectful of the needs of other children-I suggest that class-based differences in childcare ideologies were just as significant. Hays' (1996) comparison of class-specific mothering styles in the US can provide deeper insight into the tensions between ayi and volunteers. She finds that, due to disparities in material resources, reference groups and cultural milieu, working-class and poor mothers are more likely to give children set rules and demand obedience while wealthier mothers tend to emphasize negotiation, choice and self-esteem in their offspring.

Akin to the unit's caregivers, the working-class and poor mothers in Hays' study also emphasize compliance and respect for adult authority in their children, done (in part at least) because parenting in this way requires less time, money and labor for those who are materially constrained. As Hays elucidates,

An obedient and compliant child...is less demanding than an assertive and independent one. Establishing a system of standardized and strictly enforced rules requires less time and individualized attention than carefully providing the child with a set of bounded choices and negotiating with the child to establish the rules for proper behavior. (p. 94)

Viewed through this perspective, TC ayi provide care that is influenced by their working-class or poor status and by the limitations of institutional caregiving, whereby they perform all of the intensive physical labor of caring for three special needs youth during 12-hour shifts. Under these circumstances, it is logical that workers would prefer children to be docile and less demanding. In comparison, Western volunteers who have the time to play freely with children and provide intellectual stimulation mirror the affluent mothers in Hays' study; in the process of attempting to serve as "examples" for ayi to learn appropriate childcare practices they overlook the disparities in life options and material resources between themselves and workers.

Henry's situation also highlights one of the unforeseen dilemmas brought about by implementing First World practices into a non-Western, institutional context. Child-centered methods are used to nurse children back to health, draw out their unique personalities and encourage them to reach their maximum capabilities. Newly-healthy children such as Henry become self-expressive and yearn for intellectual stimulation, traits that are highly valued in First World contexts as well as in China's global cities. Yet, his severe physical disabilities, long-term dependency and the limits of the institutional setting constrain his possibilities for future growth and cause immense frustration for everyone involved.

Volunteers and working-class Chinese caregivers thus subscribe to very different views of what it means to be a "good child." Ayi, who work much more closely with children over longer periods of time, tend to take a shorter-term view of children's progress and focus primarily on immediate physical health. In the context of modernizing China where societal membership is contingent on children's potential to become creative, individualistic, entrepreneurial and productive laborers as adults, physically and mentally disabled youth are seen to lack a viable future. Thus, ayi tend to define their needs solely in the present tense.

Temporary volunteers, on the other hand, take a long-term and individualized approach to care, emphasizing children's emotional as well as physical well-being. Even though the 
mere sustainability of the unit is tenuous and contingent on political circumstances that might shift at any moment, Westerners treat children as they would in their own countries, attempting to prepare them for myriad life opportunities that may never actually become available.

\section{The material limitations of unconditional love}

The child-centered, individualistic ideologies that motivate the unit's care practices illuminate underlying tensions between money, care and intimacy that go beyond the bounds of cultural differences. Once hired, working-class and poor Chinese caregivers are expected to love children unconditionally for very little material reward, which parallels a similar situation to childcare workers in developed country contexts (see Cancian 2002; Uttal and Tuominen 1999; Wrigley 1995; Nelson 1990). The obvious disparity between the First World consumption practices within the unit and many ayis' own precarious financial situations presents a constant source of dissatisfaction and resentment, as some women are the sole income earners in their households and struggle on their low wages to support their families.

The fact that the unit's children receive expensive gifts and a seemingly endless supply of foreign clothing, diapers, bath products, toys, specialized medical equipment and Western medicine while ayi earn only 25 kuai per 12-hour shift (at the time roughly equivalent to $\$ 3.30$ US a day) was a reality entirely apparent to the Chinese staff. It was also easily ignored by volunteers, who had mostly paid their own way to China or were subsisting on donations from church congregations. By way of comparison, while ayi earned a total of 450 kuai per month, diaper costs alone averaged around 360 kuai per child each month.

Tensions over low pay and long hours came to a head during the Chinese New Year holiday, when seven ayi threatened to strike if their wages were not raised. They expressed displeasure at being required to work during the 3-week holiday, after having discovered that the ayi in the state facility below were being granted vacation leave. In the days prior to their announcement these usually diligent and compliant workers had begun to engage in everyday acts of resistance (Scott 1985) through noticeable foot-dragging, neglecting their children or ignoring volunteers' requests. The main strike organizer had begun calling in sick on a daily basis, forcing the ayi supervisor to call in untrained substitutes at the last minute. The Westerners were both shocked and deeply hurt by what they considered to be a blatant demand for money.

The TC management found itself in a difficult cultural and legal bind. Any discussions regarding finances tended to make the Western staff highly uncomfortable; when asked, they often claimed that the unit's funding "comes from God" and operated under the takenfor-granted assumption that everyone was equally committed to unconditional care for the children. TC had the financial means to pay their workers more, and the British nurse supported providing health insurance and cutting work shifts from 12 hours to eight. However, even though the organization was completely autonomous in terms of hiring and paying its ayi, its agreement with the Chinese government obligated it to pay wages and assign work shifts equivalent to the state workers on the floors below.

At the same time, as a result of their child-centered ideologies and altruistic motivations for working in China, the heads of the unit were personally offended that ayi would ever abandon their duties to the children in their care for the sake of money. They countered that at least ayi received a wage at all, while volunteers were donating their time and effort on 
behalf of children entirely without compensation. Upon much anxious deliberation and prayer, the management decided to fire all of the women who refused to come into work the next day.

The following morning, an older caregiver who was particularly well-liked and trusted by all staff members stepped forward to mediate the dispute at the last minute, convincing her colleagues to negotiate rather than strike. She explained one of the major sources of ire-the requirement that daytime caretakers were scheduled to work an exhausting six 12-hour days in a row, with only 3 days off in-between. The management argued back that the regular CWI ayi were required to work 12-hour shifts every day and received only national holidays off, implying that they were giving their own staff a highly favorable deal.

Nonplussed, the TC ayi would not be dissuaded from their stance and ultimately the employers decided they could not risk losing seven trained caregivers. While their wages could not be directly raised due to its agreement with the institution, major adjustments were made to the daytime work schedules, reducing the number of consecutive work days from six down to three while still maintaining the 3 day rest in-between. Immediately following these concessions, the caregivers' attitudes shifted considerably and they began to care for their children with the same amount of concern and attention that they had shown in the past.

This episode, however, left the Western staff shaken. For the first time they realized that their belief in sacrifice without reward did not align with the expectations and demands of their Chinese staff, who viewed their work as a job rather than as a calling. Changing work schedules involved a significant amount of labor, as a number of new caregivers needed to be hired and trained. Having more ayi also meant compromising on one of the unit's basic philosophies regarding the consistency of care for children. Yet, more than anything, this situation drew attention to the socioeconomic disparities between affluent volunteers who have the privilege of donating their time to helping marginalized children and the local women who perform caring labor due to the lack of better options.

\section{Conclusion}

Few scholars have considered the lives of children living on the margins of Chinese society. Focusing on the case of the Tomorrow's Children special care unit, I have described recent foreign involvement in the politically sensitive issue of caring for China's abandoned, institutionalized children. I have discussed the negotiations that occur when Westerners, crossing uneven and unequal national spaces, attempt to import particular assumptions, ideologies and practices of childcare into a local Chinese setting.

Possessing their own financial backing and medical expertise highly valued by the Chinese state, volunteers draw upon Western middle-class notions of childhood as a protected, nurtured time of life, which inspires practices that seek to revalue each child as a unique individual and to "give children a childhood." These methods include giving children English names, tracking their bodily and emotional development on a daily basis, and attempting to discover and encourage each child's innate talents and predispositions. In the special care unit, contrary to more traditional Chinese expectations that children will grow up to care for their parents in the future (still a common practice in primarily agricultural regions), Western volunteers appreciate special needs children in spite of their economic uselessness.

Yet, as this article has explored, the Western view of children as sacred and "priceless" is actually a result of culturally and historically specific trends that emerged alongside broader 
industrialization and urbanization. The situation in contemporary China is comparable, as meanings of children and childhood are also shifting depending on local patterns of economic and social development. Structural change has resulted in the stratification of childhoods in China, whereby pampered middle-class "only" children residing in global cities such as Beijing, Shanghai and Guangzhou have more in common with middle-class children in the industrialized global north than with those at the center of this study.

In the Tomorrow's Children unit, Chinese caregivers are expected to alter their own cultural and class-based views of appropriate childcare by implementing a formally-planned set of practices derived from Western stage theories of child development and psychology. Ayi find themselves in a situation that raises questions of power within a transnational context. While many of these working-class and poor women struggle on their low wages to make financial ends meet, issues of socioeconomic inequality among the adults in the unit are often obscured by the dominant principle of child-centeredness.

Caregivers are expected to encourage children to become individualistic and selfexpressive, which can result in conflicts over appropriate childcare practices. Keeping children docile and well-behaved serves the interests of ayi who perform the demanding physical labor of caring for disabled youth, while Westerners view the development of emotional and intellectual capacities as fundamental to what children need. Personalized care and attention often results in transforming malnourished, silent, passive beings into fat, happy and active children. But, as became obvious in Henry's case, the successful implementation of child-centered practices can also lead to unresolved frustration for youth who are limited by their institutional setting.

In an era of market competition, due to their long-term dependency and special needs, youth such as Henry will likely continue to be marginalized throughout their lives regardless of the amount of material resources and emotional labor temporarily invested in them by the unit. Henry's situation highlights the ways in which foreign aid groups, in their rush to get involved, enact change and save lives, can reach a point in their work where it becomes clear that they have not adequately considered the long-term interests of those they seek to help.

Lastly, while volunteers and ayi alike tended to view their conflicts over childcare practices through the lens of insurmountable cultural differences, I have argued that they are better explained through adding a class-based analysis of understandings of children's best interests. As demonstrated by the New Year's strike, children's care is deeply affected by socioeconomic disparities between management and staff. Ultimately, each side views their work with marginalized youth from fundamentally different vantage points depending on their access to material resources.

In conclusion, studying struggles over ideologies and practices of childcare in a transnational setting is useful in delineating the heterogeneous and contested nature of children's best interests. As Gullov (2003) writes, because children are "symbols of the time to come," places for children "are at once concrete, material loci, and symbolic expressions of social positions and expectations for the future." (p. 27) Through processes of globalization, organizations such as Tomorrow's Children are part of a new social movement in China that is attempting to change - or at least challenge-Chinese culture and practices from the ground-up. International collaborations of this kind make obvious the socially privileged nature of Western volunteerism and the often taken-for-granted ideologies that well-intentioned actors bring to countries undergoing rapid economic development. Ultimately, this research brings more nuance into discussions of globalization by exposing the tension and negotiation that occur at the local level in processes of transnational exchange. 
Acknowledgments I would like to thank my dissertation advisers Barrie Thorne and Tom Gold for their unfailing support. I am also indebted to Rachel Stern, Jenny Chio, Suowei Xiao, Jonathan Hassid, Mark Dallas and the anonymous reviewers for their insightful feedback. Finally, heartfelt thanks go out to the volunteers and caregivers who allowed me into their lives. Funding for this project was provided by the Fulbright Hays Doctoral Dissertation Research Abroad program and the University of California, Berkeley.

Open Access This article is distributed under the terms of the Creative Commons Attribution Noncommercial License which permits any noncommercial use, distribution, and reproduction in any medium, provided the original author(s) and source are credited.

\section{References}

Alston, P. (Ed.). (1994). The best interests of the child: Reconciling culture and human rights. Oxford: Clarendon.

Alwin, D. (1988). From obedience to autonomy: Changes in traits desired in children, 1924-1978. Public Opinion Quarterly, 52, 33-52.

Anagnost, A. (1995). A surfeit of bodies: Population and the rationality of the state in post-Mao China. In F. Ginsburg \& R. Rapp (Eds.), Conceiving the new world order: The global politics of reproduction (pp. 22-41). Berkeley: University of California Press.

Anagnost, A. (1997). Children and national transcendence in China. In K. Lieberthal et al. (Eds.), Constructing China: The interaction of culture and economics (pp. 195-222). Ann Arbor: Center for Chinese Studies, University of Michigan.

Anagnost, A. (2004). The corporeal politics of suzhi. Public Culture, 16, 189-208.

Bakken, B. (2000). The exemplary society: Human improvement, social control, and the dangers of modernity in China. London: Oxford University Press.

Bornstein, E. (2002). Developing faith: Theologies of economic development in Zimbabwe. Journal of Religion in Africa, 2, 4-31.

Burman, E. (1994). Innocents abroad: Western fantasies of childhood and the iconography of emergencies. Disasters, 18, 238-253.

Cancian, F. (Ed.). (2002). Child care and inequality: Rethinking carework for children and youth. NY: Routledge.

Chao, R. (1994). Beyond parental control and authoritarian parenting style: Understanding Chinese parenting through the cultural notion of training. Child Development, 65(4), 1111-1119.

Chen, X., Hastings, P., Rubin, K., Chen, H., Cen, G., \& Stewart, S. (1998). Child-rearing attitudes and behavioral inhibition in Chinese and Canadian toddlers: A cross-cultural study. Developmental Psychology, 34, 677-686.

Dorow, S. (2006). Transnational adoption: A cultural economy of race, gender, and kinship. NY: New York University Press.

Fong, V. (2002). China's one-child policy and the empowerment of urban daughters. American Anthropologist, 104, 1098-1109.

Fong, V. (2004). Only hope: Coming of age under China's one-child policy. Stanford: Stanford University Press.

Foucault, M. (1978). The history of sexuality (Vol. 1). NY: Pantheon Books.

Greenhalgh, S. (2003). Planned births, unplanned persons: "Population" in the making of Chinese modernity. American Ethnologist, 30, 196-215.

Greenhalgh, S. (2005). Governing China's population: From Leninist to neoliberal biopolitics. Stanford: Stanford University Press.

Gullov, E. (2003). Creating a natural place for children: An ethnographic study of Danish kindergartens. In K. Olwig \& E. Gullov (Eds.), Children's places: Cross-cultural perspectives (pp. 23-38). NY: Routledge.

Hardyment, C. (2007). Dream babies: Childcare advice from John Locke to Gina Ford. London: Frances Lincoln Limited Publishers.

Hays, S. (1996). The cultural contradictions of motherhood. New Haven: Yale University Press.

Hoffman, D., \& Zhao, G. (2008). Global convergence and divergence in childhood ideologies and the marginalization of children. In K. Biraimah \& W. Gaudelli (Eds.), Education and social inequality in the global culture (pp. 1-16). Dordrecht: Kluwer Academic.

Howell, S. (2006). The kinning of foreigners. NY: Berghahn Books. 
"H” Province Statistical Yearbook. ("H” Tongji Nianjian). (2007). China Statistics Press.

Jing, J. (2000). Feeding China's little emperors: Food, children, and social change. Stanford: Stanford University Press.

Johnson, K. A. (2004). Wanting a daughter, needing a son: Abandonment, adoption, and orphanage care in China. Minnesota: Yeong and Yeong.

Johnson, K. A., Huang, B., \& Wang, L. (1998). Infant abandonment and adoption in China. Population and Development Review, 24, 469-485.

Keyser, C. (2006). The role of the Chinese state in child welfare. Prepared for Presentation at the Association for Asian Studies Meeting.

Kipnis, A. (2006). Suzhi: A keyword approach. The China Quarterly, 186, 295-313.

Kusserow, A. (2004). American individualisms. NY: Palgrave MacMillan.

Lareau, A. (2003). Unequal childhoods: Class, race, and family life. Berkeley: University of California Press.

Lau, S., \& Yeung, P. (1996). Understanding Chinese child development: The role of culture in socialization. In S. Lau (Ed.), Growing up the Chinese way: Chinese child and adolescent development (pp. 29-44). Hong Kong: The Chinese University Press.

Malkki, L., \& Martin, E. (2003). Children and the gendered politics of globalization: In remembrance of Sharon Stephens. American Ethnologist, 30, 216-224.

Nelson, M. (1990). Negotiated care: The experience of family day care providers. Philadelphia: Temple University Press.

Niemetz, C. (2007). Culture of caregiving in a faith-based orphanage in northeastern China. Unpublished dissertation. Pittsburgh, PA: University of Pittsburgh.

Nieuwenhuys, O. (2003). Growing up between place of work and non-places of childhood. In K. Olwig \& E. Gullov (Eds.), Children's places: Cross-cultural perspectives (pp. 99-118). NY: Routledge.

Scott, J. (1985). Weapons of the weak: Everyday forms of peasant resistance. New Haven: Yale University Press.

Shang, X. (2001). Moving towards a multi-level and multi-pillar system: Changes in institutional care in two Chinese cities. Journal of Social Policy, 30, 259-281.

Shang, X., \& Cheng, J. (2006). Zhongguo gu'er zhuangkuang fenxi (Analysis of the situation of China's orphans). Youth Studies, 10, 8-12.

Shang, X., Wu, X., \& Li, H. (2005a). Shehui zhengce, shehui xingbie yu zhongguo de ertong yiqi wenti (Social policy, social gender and the problem of infant abandonment in China). Youth Studies, 4, 32-35.

Shang, X., Wu, X., \& Wu, Y. (2005b). Welfare provision for vulnerable children: The missing role of the state. China Quarterly, 181, 122-136.

Stephens, S. (1995). Children and the politics of culture. Princeton: Princeton University Press.

Thorne, B. (2009). 'Childhood': Changing and dissonant meanings. International Journal of Learning and Media, 1(19), 27.

Traver, A. (2007). Homeland décor: China adoptive parents' consumption of Chinese cultural objects for display. Qualitative Sociology, 30, 201-220.

Uttal, L., \& Tuominen, M. (1999). Tenuous relationships: Exploitation, emotion, and racial ethnic significance in paid child care work. Gender \& Society, 13, 758-780.

Wang, L. (2009). 'Missing girls' in an era of 'high quality': Governmental control over population and daughter discrimination in contemporary China. Social Transformations in Chinese Society, 4, 245-270.

Woodhead, M. (1997). Psychology and the cultural construction of children's needs. In A. James \& A. Prout (Eds.), Constructing and reconstructing childhood (pp. 63-84). London: Falmer.

Woronov, T. (2003). Transforming the future: 'Quality' children and the Chinese nation. Unpublished dissertation. Chicago: University of Chicago.

Wrigley, J. (1989). Do young children need intellectual stimulation? Experts' advice to parents, 1900-1985. History of Education Quarterly, 29, 41-75.

Wrigley, J. (1995). Other people's children. NY: Basic Books.

Wu, D. (1996). Chinese childhood socialization. In M. Harris (Ed.), The handbook of Chinese psychology (pp. 143-154). NY: Oxford University Press.

Xiao, H. (2000). Structure of child-rearing values in urban China. Sociological Perspectives, 43(3), 457-471.

Zelizer, V. (1985). Pricing the priceless child: The changing social value of children. Princeton: Princeton University Press.

Leslie K. Wang is a PhD candidate in Sociology at The University of California, Berkeley whose research interests include childhood, globalization, gender and qualitative methods. Her dissertation is an ethnographic study of care for abandoned children residing in Chinese state-run orphanages. 